\title{
Relations between teachers' organizational justice perceptions and organizational commitment and job satisfaction in the school: A meta-analysis
}

\author{
Kamile Demir ${ }^{1}$
}

\begin{abstract}
The purpose of this research study is to investigate the relationship between teachers' organizational justice perceptions and organizational commitment and job satisfaction in the school via meta-analysis. An extensive literature search was conducted to identify both published and unpublished reports that examined the relationship between teachers' perceptions of justice, job satisfaction and the organizational commitment to minimize potential availability bias. In total, research reports have identified providing usable data for 24 independent samples. Eight of these studies were published and 16 were unpublished dissertations. In this study, as indicator of effect size is chosen the correlation coefficient. Random effects model was preferred according to heterogeneity tests conducted for organizational commitment and job satisfaction. As a result of meta-analysis, it was found that distributive justice correlated positively with organizational commitment. There is a positive correlation between interactional justice and organizational commitment. Interactional justice has a significant relationship with organizational commitment. Teachers' overall perception of justice was positively related to organizational commitment. The distributive justice was found to have a significant relationship with teachers' job satisfaction. Procedural justice was found to be significantly related to the teachers' job satisfaction. There is a positive correlation between interactional justice and teachers' job satisfaction. Finally, organizational justice positive correlated with job satisfaction.
\end{abstract}

Keywords: Organizational Justice, Organizational Commitment, Job Satisfaction, Teacher, MetaAnalysis.

\section{Introduction}

Over the last 30 years, organizational justice has been researched extensively in organizational contexts by management researchers. The study of organizational justice perceptions also has received great attention from the researchers in the field of educational management (i.e. Burns \& Dipaola, 2013; Hoy \& Tarter, 2004; Aydın \& Kepenekci, 2008; Elma, 2013; Titrek, 2010). Justice is a perceptual phenomenon such that an act is considered fair because someone perceives it to be just (Nakra, 2014). Perceptions of justice are formed as employees examine their work-related outcomes and the procedures which regulate the distribution of those outcomes (Cropanzano \& Prehar, 2001). Additionally, justice perceptions are formed through the interpersonal treatment one receives, not only in the process and procedures which impact allocation, but also in everyday encounters on the job (Bies, 2001).

1 Associate Professor, Mehmet Akif Ersoy University, Education Faculty, Primary Education Department, kamiledemir@hotmail.com 
Demir, K. (2016). Relations between teachers' organizational justice perceptions and organizational commitment and job satisfaction in the school: A meta-analysis. International Journal of Human Sciences, 13(1), 1408-1417. doi:10.14687/ijhs.v13i1.3396

Organizational justice describes the individuals' perception of the fairness of treatment received from an organization and their behavioral reaction to such perceptions (Lam, Schaubroeck, \& Aryee, 2002). Fox, Spector, and Miles (2001) defined organizational justice as concerned with employee perceptions of fair or just treatment on the job. Moorman $(1991,845)$ stated that "organizational justice is concerned with the ways in which employees determine if they have been treated fairly in their jobs and the ways in which those determinations influence other workrelated variables".

The basis for the study of organizational justice research is Adams' (1965) equity theory. Equity theory essentially focuses the perceptions individuals establish when they make judgments about their level of inputs compared to resulting outcomes. In other words, work on justice focused on the consequences of fairness decision outcomes (Greenberg, 1987). Organizational members continually examine the relationship between their contributions to the organization and the distributions made by the organization. Those transactions result in the group members forming various perceptions regarding the climate of fairness which exists within the organization. Those fairness perceptions then emerge to shape the level of organizational justice or fairness thought to exist within the organization (Whisenant and Smucker, 2007). According to Guy (2007), although each individual assesses his or her investments and costs relative to another, there is no guarantee that each person in the exchange will make the same assumptions regarding costs, investments, and rewards for self or other.

\subsection{Dimensions of Organizational Justice}

The studies of fairness started with perceive fairness of outcomes, that is, distributive fairness (Bakhshi, Kumar, and Rani, 2009). In organizational settings, the inputs include experience, qualification and effort while the outcomes include pay, promotions and other forms of recognition. If the outcome-input ratios are not perceived to be equivalent to the ratios of others, it results in inequity (Nakra, 2014). According to Mcnabb (2009) distributive justice, in the organizational sense, refers to the perception by individuals within an organization about the relative fairness of a particular outcome. More specifically, distributive justice addresses an individual's evaluation of whether or not rewards (e.g., pay raises) are allocated fairly to employees based on their contributions to the organization. Lee (2007) stated that distributive justice refers to fairness in the distribution of rewards in an organization and relates to individual outcomes such as salary, benefits, and pay raises. Individuals' reactions to outcomes did not depend solely on the outcomes dictated by the systems. Instead, individuals compare their to referent individuals. This social comparison process formed the basis for the distributive justice concept. Colquitt, Greenberg, and Zapata-Phelan (2005) conceptualization of distributive justice stated that: (a) the action of any one individual influenced the activities of at least one other individual, (b) individuals involved in an exchange were more sensitive to the possibility that the other may gain more in the exchange, and (c) distributive justice perceptions were subjective.

Distributive justice considers the cognitive, affective, and behavioral reactions to particular outcomes (Cohen-Charash \& Spector, 2001). It is achieved when the outcomes are given in proportion to the contributions of the individual and when they make employees feel good about their jobs. It concerns whether the outcome of a decision is appropriate, moral, and ethical when compared to the referents, or benchmarks. (Folger \& Konovsky, 1998).

The study of procedural justice expanded the study of distributive justice, since findings showed that the distribution of rewards was not always as important as the process by which they were allocated (Bakhshi, Kumar, and Rani, 2009). Procedural justice which refers to the degree to which the processes and outcomes procedures used for making resource and allocation decisions are perceived to be fair (Nakra, 2014).Viswesvaran and Ones (2002) stressed that distributive 
Demir, K. (2016). Relations between teachers' organizational justice perceptions and organizational commitment and job satisfaction in the school: A meta-analysis. International Journal of Human Sciences, 13(1), 1408-1417. doi:10.14687/ijhs.v13i1.3396

justice has been defined as the fairness of the outcome itself whereas procedural justice has been defined as the fairness of the means or procedures used to determine that outcome. Procedural justice examines the influence of all throughput processes, which occur between inputs and outcomes, on perceptions of justice. (Guy, 2007). Explanations for why procedural justice effects occur have evolved around two explanations. First, from a self-interest point of view, procedural justice effects occur because individuals feel that control over organizational processes increases the chances of securing a more favorable outcome. The second explanation for the procedural justice effects is the group-value model which in contrast to the self-interest model outlined above posits that procedural justice effects occur because people are committed to their organizations/groups, value their membership, and therefore, also value the rules and procedures enacted by that group (Viswesvaran \& Ones, 2002). Typically, procedures are perceived to be 'fair' when they are consistent across people and over time, free of bias, accurate (relying on good information), contain mechanisms for correcting wrong decisions, adhere to prevalent conceptions of morality and are representative (i.e., take into account opinions of all groups affected), implying both process and decision control (Nakra, 2014). Leventhal (1980) identified six specific rules for fair procedures: (1) consistency, (2) bias suppression, (3) accuracy, (4) correctability, (5) representativeness, and (6) ethicality. Mcnabb (2009) asserted that if these factors are perceived as being met during the process, individuals will likely perceive the entire process as fair, even if they do not receive the anticipated outcome. However, if any of these standards are perceived as not being met, the fairness of the procedure may be called into question.

Meanwhile, an additional conceptualization of interactional justice emerged. Interactional justice is focused on the interpersonal side of organizational practices, specifically, the interpersonal treatment and communication by management to employees (Cohen-Charash \& Spector, 2001). Bies and Moag (1986) proposed that interpersonal treatment is conceptually distinct from the enactment of procedures. That is, interactional justice is distinct from procedural justice. Lee (2007) stated that interactional justice refers to the interpersonal treatment that employees receive from their supervisors in implementing the organization's policy and procedures Bies (2001) defined interactional justice as the concern expressed by an individual regarding the interpersonal treatment received from others. While procedural justice concerns the actual processes used to determine outcomes in an organization, interactional justice is certainly related in the sense that it involves how individuals are treated while these processes are being enacted. The interaction between parties, however, involves more than an objective determination of fair versus unfair or right versus wrong. (Mcnabb,2009). Interactional justice is most likely to be fostered when decision-makers (a) treat individuals with interpersonal dignity and (b) provide due justifications or explanations for decision-making (Nakra, 2014). Greenberg (1993) asserted to split interactional justice into two main elements: the quality of treatment covering respect and sensitivity which was categorized as informational justice and interpersonal justice that encompassed explanations and information regarding decision-making. Bies and Shapiro (1987) identified four communication criteria for fair interpersonal treatment: (1) truthfulness, (2) justification, (3) respect, and (4) propriety. Subsequent studies linked interactional justice to both attitudinal and behavioral outcomes.

\subsection{Two Outcomes Of Organizational Justice: Job Satisfaction And Organizational Commitment}

Organizational justice theory provides a useful framework to understand individuals' attitudes toward work, work behaviors, and job performance, based on their perception of fairness (justice) in the workplace (Colquitt, Conlon, Wesson, Porter, \& Ng, 2001; Cropanzano \& Greenberg, 1997).Originally, work on justice focused on the consequences of fairness decision 
Demir, K. (2016). Relations between teachers' organizational justice perceptions and organizational commitment and job satisfaction in the school: A meta-analysis. International Journal of Human Sciences, 13(1), 1408-1417. doi:10.14687/ijhs.v13i1.3396

outcomes (Greenberg, 1987). In fact, employee perceptions of fairness and justice have been linked to various individual and organizational outcomes (Viswesvaran \& Ones, 2002; Tremblay \& Roussel, 2001). The research on organization justice perceptions which focuses on the role of fairness in the school have shown that organizational justice perceptions strongly effect the attitude of the workers such as job satisfaction and organization commitment (Cohen-Charash \& Spector, 2001; Colquitt et al., 2001).For instance, Colquitt, Conlon, Wesson, Porter, and Ng (2001) conducted a meta-analytic review of 183 justice studies. The results illustrate that overall and unique relationship among distributive, procedural, interpersonal, and informational justice with job satisfaction and organizational commitment.

Job satisfaction, a multifaceted psychological construct, has been demonstrated to be an outcome of organizational justice (Lee, 2007). According to Spector (1997:2), job satisfaction is defined as "how people feel about their jobs and different aspects of their jobs." Generally speaking, the term "job satisfaction" can be conceptualized as a combination of job characteristics, work environment, and personal traits and attitudes. There are two primary theories about how organizational justice relates to job satisfaction: the personal outcomes model and the group-value model. The personal outcomes model distributive justice is a stronger predictor of job satisfaction, while the group value model argues that procedural justice is more indicative of job satisfaction. (Mcnabb,2009). So, research shows that more important predictor of job satisfaction than procedural justice (Sweeney and McFarlin, 1993; Folger and Konovsky, 1989; Alexander and Ruderman, 1987; McFarlin and Sweeney, 1992).

Organizational commitment has been demonstrated to be an outcome of organizational justice (Lee, 2007). According to Mowday, Porter, and Stears (1982), organizational commitment involves three factors: (a) a strong belief in and acceptance of the organization's goals and values, (b) willingness to exert considerable effort on behalf of the organization and (c) a strong desire to maintain membership in the organization. When this occurs and a procedure is viewed as "unfair," employees have been shown to display lower levels of organizational commitment. (Mcnabb,2009). Studies have shown that procedural justice is significantly and positively related with organizational commitment (Cobb and Frey, 1996; Tang and Sarsfield-Baldwin, 1996). Lowe and Vodanovich (1995) found that distributive justice measures accounted for more variance in both satisfaction and commitment than did procedural justice. A study by Barling and Phillips (1993) also indicated that procedural justice was a strong predictor of organizational commitment and withdrawal behaviors, while distributive justice was not.

The purpose of this research study is to investigate the relationship between teachers' organizational justice perceptions and organizational commitment and job satisfaction in the school via meta-analysis. Hence, the following hypothesis was proposed in the research:

H1. There is a positive correlation between teachers' organizational commitment and perception of distributive justice.

H2. There is a positive correlation between teachers' organizational commitment and perception of procedural justice.

H3. There is a positive correlation between teachers' organizational commitment and perception of interactional justice.

H4. There is a positive correlation between teachers' job satisfaction and perception of distributive justice.

H5. There is a positive correlation between teachers' job satisfaction and perception of procedural justice. 
Demir, K. (2016). Relations between teachers' organizational justice perceptions and organizational commitment and job satisfaction in the school: A meta-analysis. International Journal of Human Sciences, 13(1), 1408-1417. doi:10.14687/ijhs.v13i1.3396

H6. There is a positive correlation between teachers' job satisfaction and perception of interactional justice.

\section{Method}

Meta-analysis was used as the research method that combined the research findings of the studies conducted on the teachers' perceptions of justice topic in Turkey. A meta-analysis, an empirical review of relevant literature that quantitatively accumulates the results from a number of studies, will provide evidence of statistical relations among the variables of interest (Hunter \& Schmidt, 1990). Dependent variables included in analysis were teachers' job satisfaction and organizational commitment. This study mainly focuses on teachers' perception of distributive, procedural, and interactional justice.

\subsection{Literature Search}

An extensive literature search was conducted to identify both published and unpublished reports that examined the relationship between teachers' perceptions of justice, job satisfaction and the organizational commitment to minimize potential availability bias. . The search for studies to be used in the meta-analyses involved computer and manual methods. The computer search involved scanning the Council of Higher Education (YÖK), Google Academic, and Turkish National Academic Network and Information Center (ULAKBİM) databases using the key words justice, fairness, organizational justice, and teachers' perception of justice. The manual search was conducted by published studies and dissertations. These keywords were used in each database to find the studies that reported the variables of interest. The initial search identified 63 studies.

In total, research reports have identified providing usable data for 24 independent samples. Eight of these studies (33\%) were published and $16(67 \%)$ were unpublished dissertations.

\subsection{Inclusion and Exclusion Criteria}

To be included in this meta-analysis, studies had to meet four criteria. The studies used in this study should conform to the following criteria: (1) the study has to be an empirical research; (2) To be included in analyses; a study had to report parametric statistics with relevant variables. (3) The study had to report on correlations; (4) partial correlations, regression coefficients, or path coefficients were excluded from the analysis; (5) Because of multiple methods of data collection, sometimes two studies were reached by the same author. For example, when one version of a study was collected as a dissertation and another version was found in a publication. If the two versions had reached, unpublished one was only used.

Based on these criteria, it was identified 24 independent studies, reporting 96 correlations teachers' perception of justice with job satisfaction and organizational commitment. The dates for the studies ranged from 2007 to 2014, and the sample size was 11869 teachers.

\subsection{Coding Procedures}

All data were combined into one data set for this analysis. In situations where multiple studies were reported in one publication, each study was treated as an independent study. As part of the analysis, the following information was coded: (1) the correlations of job satisfaction and organizational commitment with perception of justice; (2) information on measures used; (3) the sample characteristics and sample sizes; and (4) the type(s) of justice. Organizational justice includes perception of distributive justice, procedural justice, and interactional justice. 
Demir, K. (2016). Relations between teachers' organizational justice perceptions and organizational commitment and job satisfaction in the school: A meta-analysis. International Journal of Human Sciences, 13(1), 1408-1417. doi:10.14687/ijhs.v13i1.3396

\subsection{Meta-analytic Procedures}

In this study, as indicator of effect size is chosen the correlation coefficient. If necessary, an average correlation was used. This study followed Cooper's (2010) guidelines for meta-analysis. The meta analytical results were found by first converting all correlation coefficients to $z$ scores, then averages were found in terms of the $z$ scores, then each averaged-z score was converted back to $r$. This resulted in overall mean weighted effect sizes for the justice variable's relationship on job satisfaction and organizational commitment.

\subsection{Publication Bias Check}

Publication bias is the term for what occurs whenever the research that appears in the published literature is systematically unrepresentative of the population of completed studies. (Rothstein, Sutton \& Borenstein, 2005). Random effects model was preferred according to heterogeneity tests conducted for organizational commitment $(\mathrm{Q} 45=711.25, \mathrm{p}<0.05)$ and job satisfaction $(\mathrm{Q} 22=451.29, \mathrm{p}<0.05)$. Two publication bias tests were completed to evaluate the potential presence and degree of potential publication bias: The Begg and Mazumdar rank correlation test (tau $\mathrm{b}=0.15 ; \mathrm{p}>.05$ ) and (b) the trim and fill test supplemented with the contour-enhanced funnel plot. All analyses were conducted using computer programs.

\section{Results}

Results of the meta-analysis conducted to establish the relationship between the perceptions of justice and organizational commitment constructs are provided in Tables 1 . As predicted, the three types of justice showed different associations with organizational commitment. It was found that distributive justice correlated positively with organizational commitment $(r=0,35$, $\mathrm{p}<0.01)$. The $95 \%$ confidence interval for distributive justice on organizational commitment ranged from 0.24 to 0.46 thus, indicating that the hypothesis that distributive justice will have a significant relationship with organizational commitment was confirmed. The overall effect size for organizational justice was large.

Table 1. Meta-Analysis of Relations between Organizational Justice and Organizational Commitment

\begin{tabular}{lllllll}
\hline & $\begin{array}{l}\text { Number } \\
\text { Studies }\end{array}$ & $\begin{array}{l}\text { Point } \\
\text { estimate }\end{array}$ & $\begin{array}{l}\text { Lower } \\
\text { limit }\end{array}$ & $\begin{array}{l}\text { Upper } \\
\text { limit }\end{array}$ & Z-value & P-value \\
\hline Distributive & 10 & 0.35 & 0.24 & 0.46 & 5.72 & 0.00 \\
Procedural & 10 & 0.41 & 0.33 & 0.48 & 9.32 & 0.00 \\
Interactional & 10 & 0.38 & 0.28 & 0.47 & 6.93 & 0.00 \\
Org. Justice & 16 & 0.42 & 0.35 & 0.48 & 10.74 & 0.00 \\
\hline
\end{tabular}

Procedural justice and organizational commitment were significantly correlated $(\mathrm{r}=0.41, \mathrm{p}$ $<0.01$ ). The $95 \%$ confidence interval for procedural justice on organizational commitment ranged from 0.33 to 0.48 thus, indicating that the hypothesis that procedural justice will have a significant relationship with organizational commitment was confirmed. There is a positive correlation between interactional justice and organizational commitment $(r=0.38 ; p<0.01)$. The $95 \%$ confidence interval for interactional justice on organizational commitment ranged from 0.28 to 0.47 thus, indicating that the hypothesis that interactional justice will have a significant relationship with organizational commitment was confirmed. Teachers' overall perception of justice were positively related to organizational commitment $(r=0.42 ; p<0.01)$. The 95\% 
Demir, K. (2016). Relations between teachers' organizational justice perceptions and organizational commitment and job satisfaction in the school: A meta-analysis. International Journal of Human Sciences, 13(1), 1408-1417. doi:10.14687/ijhs.v13i1.3396

confidence interval for justice on organizational commitment ranged from 0.35 to 0.48 thus, indicating that the hypothesis that justice will have a significant relationship with organizational commitment was confirmed. Subgroup analyses conducted for the organizational justice variable revealed that procedural justice correlated more strongly with organizational commitment.

Table 2. Meta-Analysis of Relations between Organizational Justice and Job Satisfaction

\begin{tabular}{lllllll}
\hline & $\begin{array}{l}\text { Number } \\
\text { Studies }\end{array}$ & $\begin{array}{l}\text { Point } \\
\text { estimate }\end{array}$ & $\begin{array}{l}\text { Lower } \\
\text { limit }\end{array}$ & $\begin{array}{l}\text { Upper } \\
\text { limit }\end{array}$ & Z-value & P-value \\
\hline Distributive & 5 & 0.47 & 0.31 & 0,61 & 5.13 & 0.00 \\
Procedural & 5 & 0.47 & 0.28 & 0.62 & 4.52 & 0.00 \\
Interactional & 5 & 0.47 & 0.32 & 0.60 & 5.48 & 0.00 \\
Org. Justice & 8 & 0.44 & 0.29 & 0.56 & 5.40 & 0.00 \\
\hline
\end{tabular}

Table 2 presents the results of the meta-analysis concerning the relations between the organizational justice and job satisfaction. The distributive justice were found to have a significant relationship with teachers' job satisfaction $(\mathrm{r}=0.47)$. The $95 \%$ confidence interval for distributive justice on job satisfaction ranged from 0.31 to 0.61 thus, indicating that the hypothesis that interactional justice will have a significant relationship with organizational commitment was confirmed. The $95 \%$ confidence interval for procedural justice on job satisfaction ranged from 0.28 to 0.62 thus, indicating that the hypothesis that procedural justice will have a significant relationship with job satisfaction was confirmed. Procedural justice were found to be significantly related to the teachers' job satisfaction $(r=0.47)$. There is a positive correlation between interactional justice and teachers' job satisfaction $(\mathrm{r}=0.47)$. The 95\% confidence interval for interactional justice on teachers' job satisfaction ranged from 0.32 to 0.60 thus, indicating that the hypothesis that interactional justice will have a significant relationship with teachers' job satisfaction was confirmed. Finally, organizational justice positive correlated with job satisfaction $(\mathrm{r}=0.44)$. The $95 \%$ confidence interval for justice on teachers' job satisfaction ranged from 0.29 to 0.56 thus, indicating that the hypothesis that justice will have a significant relationship with job satisfaction was confirmed.

\section{Conclusions and Suggestions}

This meta-analysis was summarized the existing data concerning teachers' perceptions of organizational justice in relation to their organizational commitment and job satisfaction. Therefore, the specific issues were examined dealt with the (a) justification of studying three relational types of organizational justice: distributive, procedural, and interactional; and (b) organizational commitment and job satisfaction. An extensive literature search was conducted to identify both published and unpublished reports that examined the relationship between teachers' perceptions of justice, job satisfaction and the organizational commitment to minimize potential availability bias. . These keywords were used in each database to find the studies that reported the variables of interest. The initial search identified 63 studies. In total, research reports have identified providing usable data for 24 independent samples. Eight of these studies were published and 16 were unpublished dissertations. In this study, as indicator of effect size is chosen the correlation coefficient. As predicted, the three types of justice showed different associations with organizational commitment.

As a result of meta-analysis, it was found that distributive justice correlated positively with organizational commitment. There is a positive correlation between interactional justice and 
Demir, K. (2016). Relations between teachers' organizational justice perceptions and organizational commitment and job satisfaction in the school: A meta-analysis. International Journal of Human Sciences, 13(1), 1408-1417. doi:10.14687/ijhs.v13i1.3396

organizational commitment. Interactional justice has a significant relationship with organizational commitment. Teachers' overall perception of justice was positively related to organizational commitment. The perception of organizational justice facilitates employees to evaluate their organization positively, encouraging them to be more strongly committed to the interests of the organization (Cohen-Charash and Spector, 2001).Subgroup analyses conducted for the organizational justice variable revealed that procedural justice correlated more strongly with organizational commitment. Studies have shown that organizational commitment is usually predicted to be related mainly to procedural justice. procedural justice is significantly and positively related with organizational commitment (Cobb and Frey, 1996; Tang and SarsfieldBaldwin, 1996; Lowe and Vodanovich, 1995; Barling and Phillips, 1993; Cohen-Charash and Spector, 2001; Folger and Konovsky, 1989; Nakra, 2014). In accordance with these predictions, the results of this research show organizational commitment to be significantly more strongly related to procedural justice than to distributive justice or to interactional justice, although the latter two are highly related to commitment as well. Nakra (2014) stated that procedural fairness symbolically communicates to employees that they are held in high regard, satisfying their needs for self-esteem and for inclusion. Further, employees demonstrate greater loyalty and willingness to behave in organization's best interests as the adoption of fair procedures generates the confidence of receiving fair treatment in the long run. Unfair procedures, on the other hand, communicate disrespect and marginality within the organization. Thus, even when distributive justice is low, more positive attitudes can be expected when employees perceive organizational procedures to be fair. Fair procedures thus provide a substantial return in the form of positive work-related attitudes.

Job satisfaction is same and highly related to all three justice types. It argued that if employees find their organization just and fair in distribution, processes and interactional system, employees feel more satisfied in job. The distributive justice was found to have a significant relationship with teachers' job satisfaction. Procedural justice was found to be significantly related to the teachers' job satisfaction. There is a positive correlation between interactional justice and teachers' job satisfaction. Finally, organizational justice positive correlated with job satisfaction. This finding, however, stands in contrast to previous empirical research (Mcnabb, 2009; Sweeney and McFarlin, 1993; Folger and Konovsky, 1989; Alexander and Ruderman, 1987; McFarlin and Sweeney, 1992) that typically has found job satisfaction to be more strongly related to various measures of procedural justice. This is contrary to the prediction that job satisfaction will be related to procedural justice more than to distributive justice. It is suggested that researchers should be examined in the dimensions of organizational commitment in relation with organizational justice. In addition, internal motivators which it is directly related to job satisfaction can be investigated.

\section{References}

Alexander, S., \& Ruderman, M. (1987). The role of procedural justice and distributive justice in organizational behavior. Social Justice Research, 1: 117-198.

Aydin, I. and Kepenekci, Y.K. (2008), Principals' opinions of organisational justice in elementary schools in Turkey. Journal of Educational Administration, 46(4), 497-513.

Bakhshi, A., Kumar, K., \& Rani, E. (2009). Organizational justice perceptions as predictor of job satisfaction and organization commitment. International Journal of Business and Management, 4 (9), 145-154.

Barling, J. and Phillips, M. (1993). Interactional, formal, and distributive justice in the workplace: an exploratory study. Journal of Psychology, 123(6), 641- 649. 
Demir, K. (2016). Relations between teachers' organizational justice perceptions and organizational commitment and job satisfaction in the school: A meta-analysis. International Journal of Human Sciences, 13(1), 1408-1417. doi:10.14687/ijhs.v13i1.3396

Bies, R. J. (2001). Interactional (In) justice: The sacred and the profane. In J. Greenberg \& R. Cropanzano (Eds.), Advances in organizational justice. Stanford, CA: Stanford University Press.

Bies, R. J., \& Moag, J. F. (1986). Interactional justice: Communication criteria of fairness. In R. L. Lewicki, B. H. Sheppard, \& R. J. Bies (Eds.), Research on negotiations in organizations. Greenwich, CT: JAI Press.

Bies, R. J., \& Shapiro, D. L. (1987). Interactional fairness judgments: The influence of causal accounts. Social Justice Research, 1, 199-218.

Burns, T. \& DiPaola, M. (2013, Fall). A study of organizational justice, organizational citizenship behavior, and student achievement. American Secondary Education. 42 (1) 4-24.

Cobb, A.T. \&Frey, F.M. (1996). The effect of leader fairness and pay outcomes on superior/subordinate relations. Journal of Applied Social Psychology, 26, 1401-1426.

Cohen-Charash, Y., \& Spector, P.E. (2001). The role of justice in organizations: A meta-analysis. Organizational Behaviour and Human Decision Processes, 86(2), 278-321.

Colquitt, J. A., Colon, D. E., Wesson, M. J., Porter, C. O., \& Ng, K. Y. (2001). Justice at the millennium: A meta-analytic review of 25 years of organizational justice research. Journal of Applied Psychology, 86(3), 425-445.

Colquitt, J., Greenberg, J., \& Zapata-Phelan, C. P. (2005). What is organizational justice? A historical overview. In J. Greenberg \& J. Colquitt (Eds.), Handbook of organizational justice (pp. 3-56). Mahwah, NJ: Lawrence Erlbaum Associates.

Cooper, H. (2010). Research Synthesis and Meta-Analysis. C.A.:Sage Pub.

Cropanzano, R., \& Prehar, C. A. (2001). Emerging justice concerns in an era of changing psychological contracts. In R. Cropanzano (Ed.), Justice in the workplace. From theory to practice. Mahwah, NJ: Lawrence Erblaum Associates, Inc.

Dailey, R. C, \& Kirk, D. J. (1992). Distributive and procedural justice as antecedents of job dissatisfaction and intent to turnover. Human Relations, 45, 305-317.

Elma, C. (2013).The Predictive Value of Teachers' Perception of Organizational Justice on Job Satisfaction. Eurasian Journal of Educational Research, 51, 157-176.

Folger R. \& Konovsky, M. (1989). Effects of procedural and distributive justice on reactions to pay raise decisions. Academy of Management Journal, 32, 851-866.

Fox, S., Spector, P. E., \& Miles, D. (2001). Counterproductive work behavior (cwb) in response to job stressors and organizational justice: some mediator and moderator tests for autonomy and emotions. Journal of Vocational Behavior, 59, 291-309.

Greenberg, J. (1987). A taxonomy of organizational justice theories. Academy of Management Review, 12(1), 9-22.

Greenberg, J. (1990). Organizational justice: Yesterday, today, and tomorrow. Journal Management, 16, 399-432.

Greenberg, J. (1993). Justice in the Workplace: Approaching Fairness in Human Resource Management. In R. Cropanzano (Eds.). The Social Side of Fairness: Interpersonal and Informational Classes of Organizational Justice. Hillsdale, NJ: Lawrence Erlbaum Associates.

Guy, S. L. (2007). Organizational justice perceptions in Virginia high schools: a study of its relationship to school climate and faculty trust. Doctoral Dissertation. UMI Number: 3300278

Hoy W.K. \& Tarter, C. J. (2004). Organizational justice in schools: no justice without trust. International Journal of Educational Management, 18 (4), 250-259.

Hunter, J. E., \& Schmidt, F. L. (1990). Methods of meta-analysis: Correcting for error and bias in research findings. Newbury Park, CA: Sage.

Lam, S. S. K.; Schaubroeck, J.; \& Aryee, S. (2002). Relationship between Organizational Justice and Employee Work Outcomes: A Cross-National Study. Journal of Organizational Behavior, 23 (1), 1-18. 
Demir, K. (2016). Relations between teachers' organizational justice perceptions and organizational commitment and job satisfaction in the school: A meta-analysis. International Journal of Human Sciences, 13(1), 1408-1417. doi:10.14687/ijhs.v13i1.3396

Lee, A.J. (2007). Organizational justice: a mediated model from individual well-being and social exchange theory perspectives. Doctoral Dissertation. CA: Touro University International. UMI Number: 3254316.

Leventhal, G. S. (1980). What should be done with equity theory? New approaches to the study of fairness in social relationship. In K. Gergen, M. Greenberg \& R.Willis (Eds.). Social exchange: Advances in theory and research.New York: Plenum Press.

Lowe, R.H. and Vodanovich, S.J. (1995). A field study of distributive and procedural justice as predictors of satisfaction and organizational commitment. Journal of Business and Psychology, 10:99-114.

McFarlin, D. B., \& Sweeney, P. D. (1992). Distributive and procedural justice as predictors of satisfaction with personal and organizational outcomes. Academy of Management Journal, 35, 626-637.

Mcnabb, N. S. (2009). The daily floggings will continue until morale improves: An examination of the relationships among organizational justice, job satisfaction, organizational commitment and intention to turnover. Doctoral Dissertation. Oklahoma: University Of Oklahoma. UMI Number: 3352987.

Moorman, R. H. (1991). Relationship between organizational justice and organizational citizenship behaviors: Do fairness perceptions influence employee citizenship? Journal of Applied Psychology, 76(6), 845-855.

Mowday, R., Porter, L., \& Steers, R. (1982). Employee organization linkages: the psychology of commitment, absenteeism, and turnover. NY: Academic Press.

Nakra, R. (2014). Understanding the Impact of Organizational Justice on Organizational Commitment and Projected Job Stay among Employees of the Business Process Outsourcing Sector in India. Vision, 18(3) 185-194.

Rothstein, H. R., Sutton, A.J. \& Borenstein, M. (2005). Publication bias in meta-analysis. In H.R. Rothstein, A.J. Sutton, \& M. Borenstein (Eds.). Publication bias in meta-analysis : prevention, assessment and adjustments. NJ: Wiley \& Sons.

Spector, P. E. 1997. Job satisfaction: Application, assessment, causes, and consequences. Thousand Oaks, CA.: Sage Pub.

Tang, T.L. \& Sarsfield-Baldwin, L.J. (1996). Distributive and procedural justice as related to satisfaction and commitment. S.A.M. Adwenced Management Journal, 61 (3), 25-31.

Titrek, O. (2010). The change of school employees' organizational justice (oj) perceptions concerning geography according to socio-culture. Eurasian Journal of Educational Research, 38, 179-197.

Viswesvaran, C. \& Ones, D.S. (2002). Examining the construct of organizational justice: a metaanalytic evaluation of relations with work attitudes and behaviors. Journal of Business Ethics, 38, 193-203.

Whisenant, W. \& Smucker, M. (2007). Organizational justice and job satisfaction: perceptions among coaches of girls' teams. Journal of Research, 2 (2), 47-53. 